\title{
Assessment of the New Faliron steam-electric station in Greece
}

\author{
C. Maraveas ${ }^{1,2}$, K. Tasiouli ${ }^{1} \&$ Z. Fasoulakis ${ }^{1}$ \\ ${ }^{1}$ C. Maraveas Partnership Consulting Engineers, Greece \\ ${ }^{2}$ School of MACE, University of Manchester, UK
}

\begin{abstract}
The New Faliron steam-electric station, the first one in Greece, is a listed historical building. The initial structure was constructed at the start of the $20^{\text {th }}$ century but a number of interventions followed until the 1960s. The structure was built with natural stone masonry, steel trusses and floors (with jack arches and joist fillers) and concrete floors reinforced with twisted cold formed rebars. The $12.5 \mathrm{~m}$ high masonries practically lack any lateral restraints while large openings (doors, windows) exist. This paper presents brief information on the history of the structure, phases of construction, description of structure (dimensions, types of structural systems, etc), material properties and pathology. In addition, detailed information is presented regarding the assessment performed in accordance with the current code specifications (Eurocodes), including seismic actions. Especially for the masonry, a detailed finite element model was developed, whereas the seismic forces were evaluated through alternative methodologies (modal response spectrum analysis per EC8 and time history analyses). For the assessment of the RC part a displacement based methodology was applied as it is restrained by the surrounding masonry walls. From the assessment analysis, useful conclusions are drawn regarding the seismic performance of high masonry structures without lateral restraints and the behaviour of similar industrial structures under seismic effects.

Keywords: historical structures, earthquake resistance, capacity assessment.
\end{abstract}

\section{Introduction}

It is widely accepted that historical masonry structures are prone to damage and deterioration, which makes their protection a major priority. As a result, many 
methods and technologies have been developed [1-6] in order to preserve both the safety and authenticity of the structural heritage with respect to the historic value of the building.

This paper presents the strengthening proposal for the first steam-electric station in Greece, located in New Faliron of Athens. The historical structure under examination, constructed in 1902, has suffered tremendous disasters due to environmental or human induced impacts. In addition, the new use of the structure as a Museum of Electric Power introduces increased capacity demands.

Particular attention is given to the finite element analysis [7] and the appraisal methods which are considered of major importance for the remaining robustness of the structure. Finally, both European Specifications (Eurocodes) [8-12] and British Standards $[13,14]$ are implemented for the capacity assessment of the existing structure.

\section{Historical review}

The first steam-electric station in Greece operated for the first time in 1903, producing $3000 \mathrm{~kW}$ of energy, placed nearby the Piraeus port, which had already been demonstrating a major role of industrial activity by the middle of the $19^{\text {th }}$ century. The position of the station was also beneficial due to the presence of Kifissos River. Until 1906, power supply had been performed to the AthensPiraeus railway, neighbouring industries and other agricultural activities, while in general its operation was related with the electrification of Athens. The increasing demands of electricity led to many alterations and interventions of the structure until 1930, while the production stopped during the $2^{\text {nd }}$ world war. In 1953 the Public Power Corporation took over the control until its final shutdown in 1972.

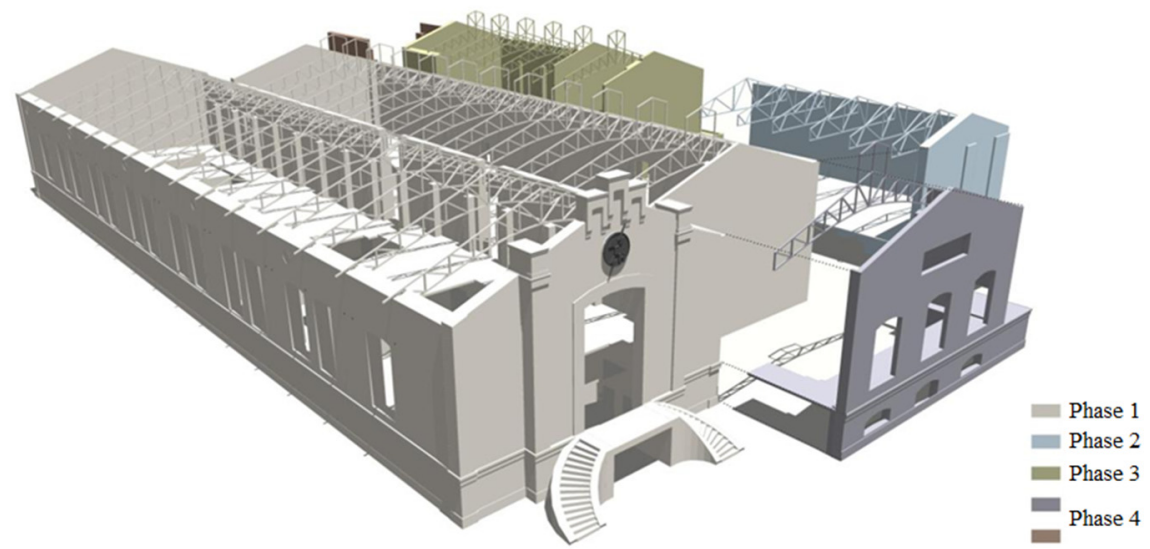

Figure 1: $3 \mathrm{D}$ representation of the structural interventions. 
An important step in the process of assessing the pathology of the building is to understand its initial construction and its evolution in time. For the examined building there are four basic construction phases which are summarily described below. The initial structural system was modified during the 1930's and 1950's, while the last intervention a few years ago (removing the roof sheeting) contributed to the mechanical properties' deterioration.

In 1902, the initial building is constructed, consisting of buildings A and B and including the steel roof that exists nowadays. In 1926, the first part of building $\mathrm{C}$ is added and several modifications take place at the mezzanine level of buildings A and B (phase 2). In 1930, the second part of building C is constructed and masonry walls are added at the transverse direction of building B. The structural interventions are completed in 1952 with the extension of building $\mathrm{C}$, necessitated by higher machinery demands. In addition, building $\mathrm{B}$ is extended through a reinforced concrete structure, while a part of the north wall is replaced by a reinforced concrete frame. The construction phases are clearly presented in Figure 1, with the corresponding buildings A, B and C illustrating from left to right, whereas views of the initial structure, depicted in 1902, are attached to the following figure.
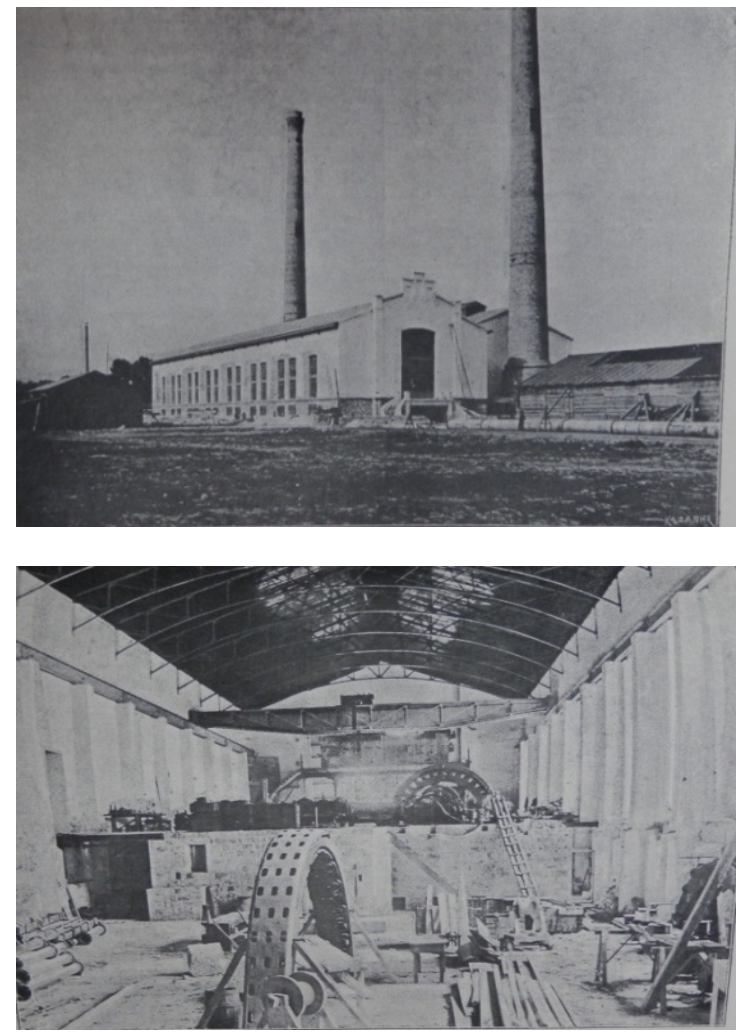

Figure 2: Historical views of the original building (1902). 


\section{Description of the structure}

The total plan of the existing building has a rectangular layout, consisting of three longitudinal parts (A, B and C) with a total surface of approximately $4187 \mathrm{~m}^{2}$. Both exterior and interior views are attached to the following figures (Figures 3 and 4). The mezzanine floor (which supports the machinery) and the roof level are $3 \mathrm{~m}$ and $12 \mathrm{~m}$ above the ground level, respectively. The thickness of the $12.5 \mathrm{~m}$ high masonry walls varies from $0.8 \mathrm{~m}$ at the top to $1.3 \mathrm{~m}$ at the base, whereas the buttresses thickness is about $0.6 \mathrm{~m}$. Furthermore, the masonry walls contain large openings (covering areas up to $5.9 \mathrm{~m} \times 2.7 \mathrm{~m}$ ), at the top of which steel beams have been introduced for supporting reasons (Figure 5). The roof consists of steel trusses of varying height $(1.3 \mathrm{~m}$ at the edges and $2.55 \mathrm{~m}$ at the middle) with fastened double-angle members. The lower flange of the trusses is arc-shaped and they are pinned on the masonry walls. Finally, steel crane bridges still exist at both $\mathrm{A}$ and $\mathrm{C}$ buildings.

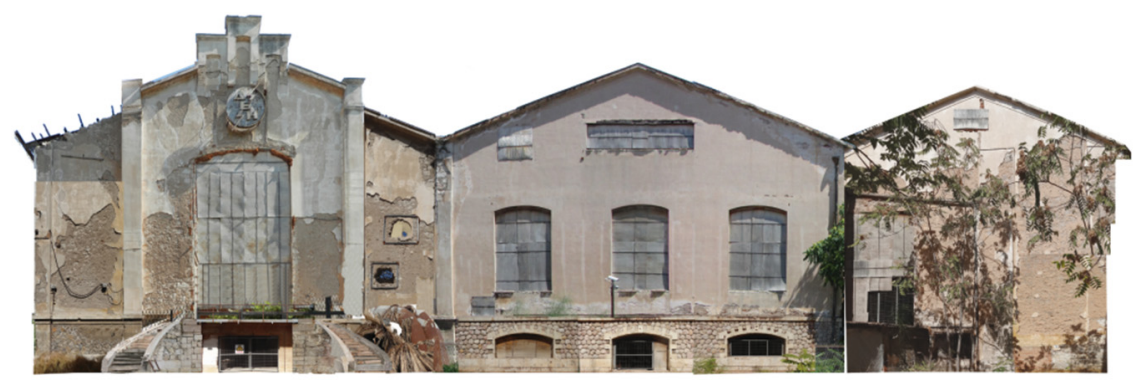

Figure 3: Exterior view of the existing structure.
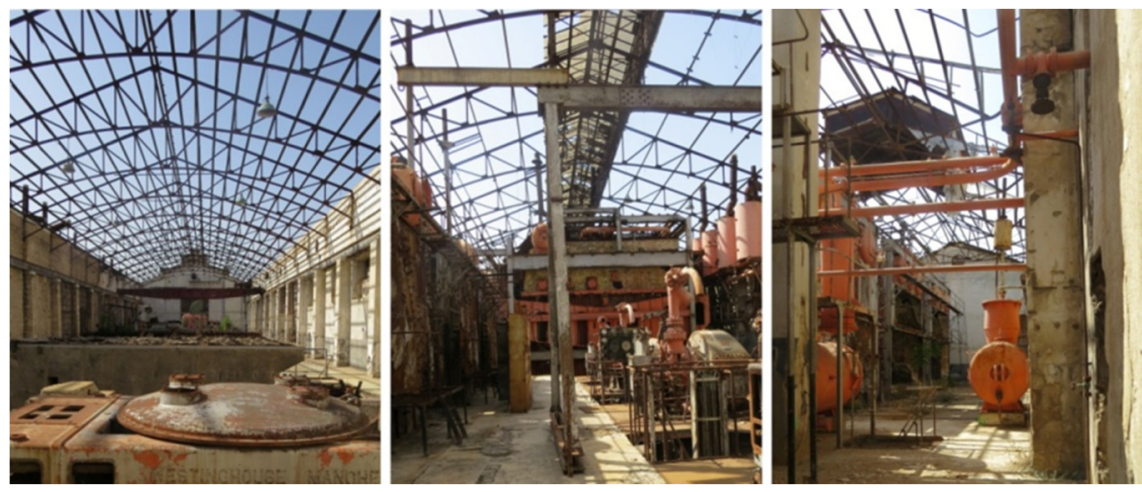

Figure 4: Interior views of the tree buildings A, B and C2 (from left to right) on the mezzanine level. 


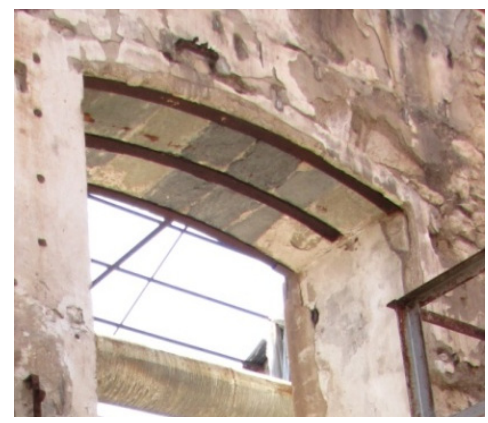

Figure 5: Configuration of a lintel supported by steel beams and concrete plates.

\subsection{Material properties: structural behaviour}

The mechanical properties of the masonry walls were determined from laboratory tests on samples taken from the field. In particular, a large amount of tests was performed for the compressive strength establishment of the concrete and stone masonry. Moreover, mortar and structural steel properties were evaluated through chemical analyses and hardness tests, respectively, while tensile tests were conducted for the reinforcing steel strength evaluation. In Table 1, the established properties are presented in detail, whereas the mean compression strength $\left(f_{b}\right)$ is established for variation coefficient, $\mathrm{CV}<25 \%$.

Table 1: $\quad$ Material mechanical properties.

\begin{tabular}{|c|c|c|}
\hline Masonry & $\begin{array}{c}\text { Structural/ } \\
\text { reinforcement steel }\end{array}$ & Concrete \\
\hline$f_{b}=55 \mathrm{MPa}$ & AISI1010 & $\mathrm{C} 12 / 15$ \\
\hline$f_{m}=0.50 \mathrm{MPa}$ & $\mathrm{S} 220$ & \\
\hline
\end{tabular}

It should be highlighted that parts of the concrete structure with high capacity demands had been reinforced with twin twisted bars, according to BS1144 [14]. These reinforcements were manufactured via cold-processing, using common steel rebars. An example of a concrete member reinforced with twin twisted bars is illustrated in Figure 6. An extended in-site survey was followed for the proper determination of the location and the number of steel rebars, using electromagnetic or destructive techniques. Finally, the visual inspection revealed that the concrete was in the most unfavourable condition due to environmental factors, while both the reinforcing and the structural steel had been extensively corroded.

Regarding the structural system, one can easily conclude that the existing roof's incompleteness and insufficient bracing lead to lack of horizontal diaphragmatic function, resulting in the inability of the main shell of the building to carry lateral forces. Especially the case of a free standing wall in $\mathrm{C} 2$ should be mentioned, the results of which are expected the most unfavourable. The 


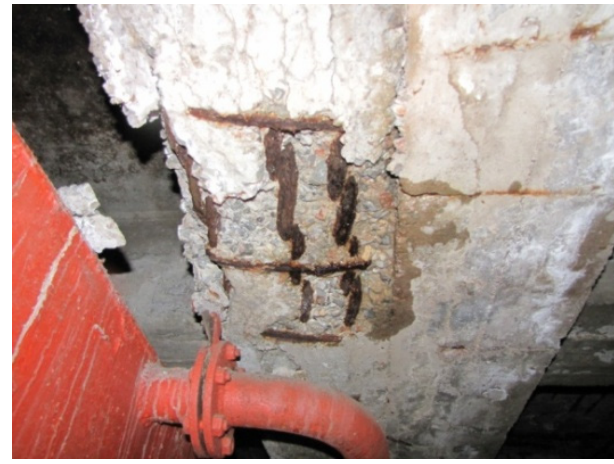

(a)

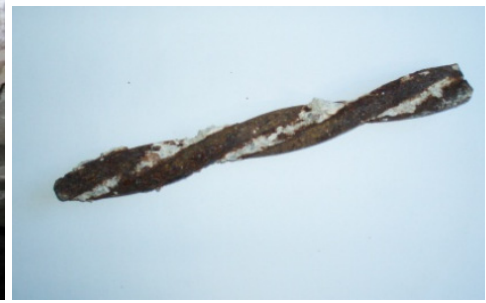

(b)

Figure 6: Views of (a) a structural member with twin twisted bars and (b) a twin twisted bar taken from the field.

mezzanine level consists of concrete frames, the horizontal members of which have been fixed to the masonry walls, or steel frames composed by jack arches and joist fillers.

\subsection{Design principles}

Eurocode Specifications were implemented in order to assess the load-bearing behaviour of the structure, namely EC2 [9] for concrete members, EC3 [10] for steel members, EC6 [11] for masonry and EC8 [12] for the seismic analysis of the structure. The imposed loads followed the specifications of EC1 [8].

On the basis of EC8, an inelastic response spectrum was adopted for soil type $\mathrm{D}$ (soil factor $\mathrm{S}=1.35$ and characteristic response spectrum periods $\mathrm{T}_{\mathrm{B}}=0.20 \mathrm{sec}$, $\mathrm{T}_{\mathrm{C}}=0.80 \mathrm{sec}$ and $\mathrm{T}_{\mathrm{D}}=2.0 \mathrm{sec}$ ), design ground acceleration $\mathrm{a}_{\mathrm{g}}=0.16 \mathrm{~g}$, importance factor $\gamma_{\mathrm{I}}=1.40$ and behaviour factor $\mathrm{q}=1.50$. According to the same regulation, it should be noted that half the elastic modulus of the masonry was adopted for the seismic response, to account for the influence of cracking.

Reinforced concrete parts that were constructed in 1950 had been designed in compliance with the existing regulations, i.e. CP114 (1948) [13]. Thus, the structural appraisal of the aforementioned cold twisted bars should be examined according to the relevant specifications, which include stress-limit design.

\section{Numerical analysis}

\subsection{Finite element simulation}

After the proper simulation of the existing structure, the masonry stress distribution was investigated, aiming at the detection of the most critical areas.

Particular attention was given to the realistic simulation of the geometry of the structure. The mathematical model was simulated, with the aid 
of commercial software [7], as a spatial model, using plate elements for the walls and beam elements for the beams/columns, including concrete neighbouring structures. The basement and steel structures connecting with the main shell structure at approximately $3.1 \mathrm{~m}$ height, provide partial lateral restraints, which were adopted at the model. In Figure 7, 3D views of the main model are presented, while the steel roofs were examined independently (Figure 8) and their reactions were introduced as forces acting on the corresponding masonry locations of the main model. The same procedure was followed for the steel structures supported on the masonry.
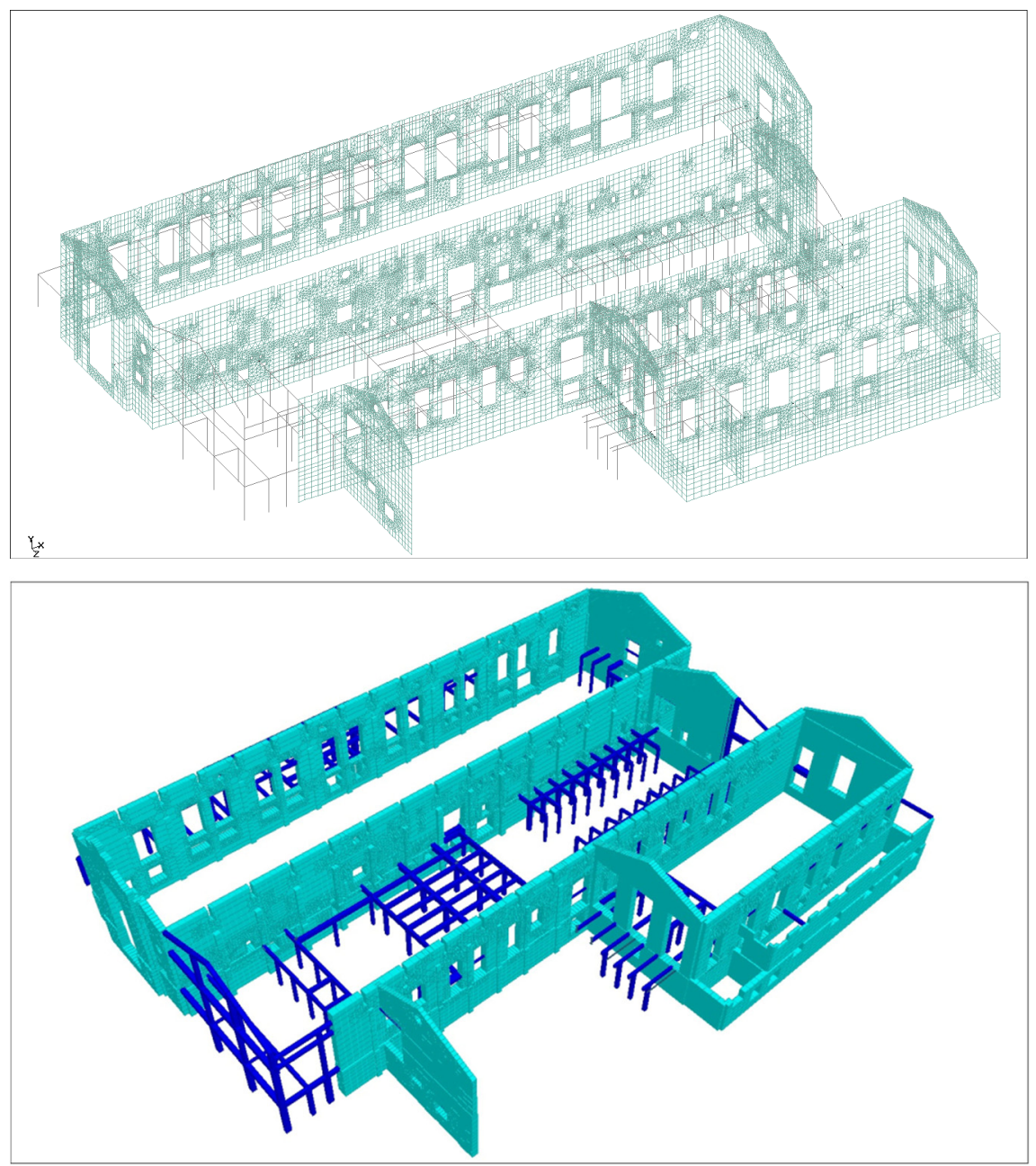

Figure 7: 3D views of the model used to simulate the existing structure. 

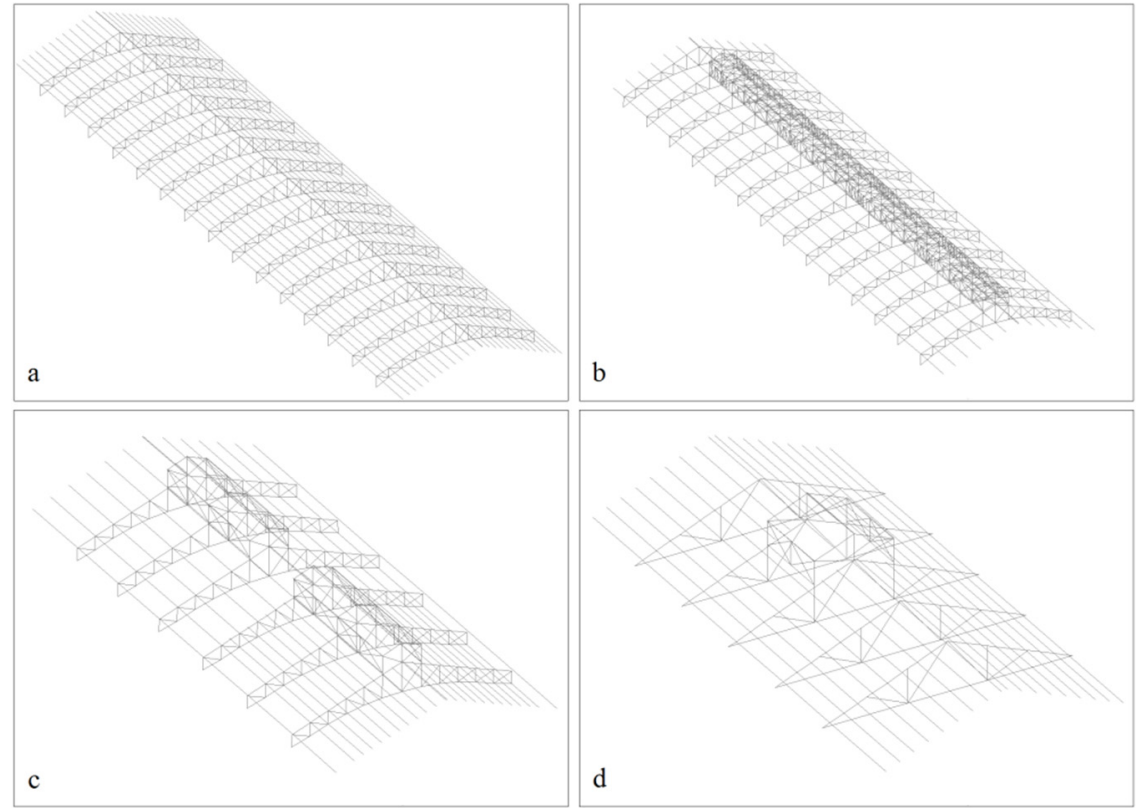

Figure 8: 3D views of the steel roofs of buildings: (a) A, (b) B, (c) C1 and (d) $\mathrm{C} 2$.
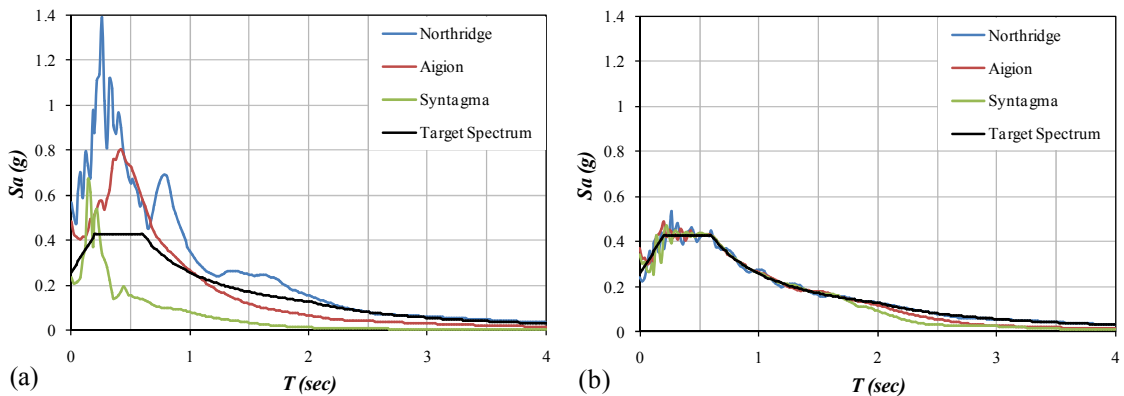

Figure 9: (a) Normalized and (b) matched response acceleration spectra compared to the corresponding one per EC8.

Modal response spectrum analysis was performed, considering the participation of 500 modes. The seismic action was also investigated through dynamic time history analyses, considering a variety of earthquake events, namely Aigion (1995), Athens (Syntagma, 1999) and Northridge (1994). The original accelerograms were scaled using SeismoMatch software [15], in order to adjust the ground motion records to the spectrum defined in the design code (target spectrum) [12]. Figures 9(a) and 9(b) display the response spectra of the normalized records and the matched spectra along with the target spectrum respectively. 


\section{Results: structural evaluation}

The results extracted from the aforementioned analysis, were thoroughly examined in order to evaluate the remaining capacity of the existing structure.

Global stress analyses were carried out, the results of which are schematically presented in Figure 10. The existing structure analysis has confirmed the decisive role of the lateral restraints. For seismic excitation with maximum magnitude $0.45 \mathrm{~g}$, enormous tensile stresses are produced (up to $5 \mathrm{MPa}$ ), whereas the overall displacements of the masonry in the horizontal directions X, Z reach $200 \mathrm{~mm}$ and $130 \mathrm{~mm}$, respectively.
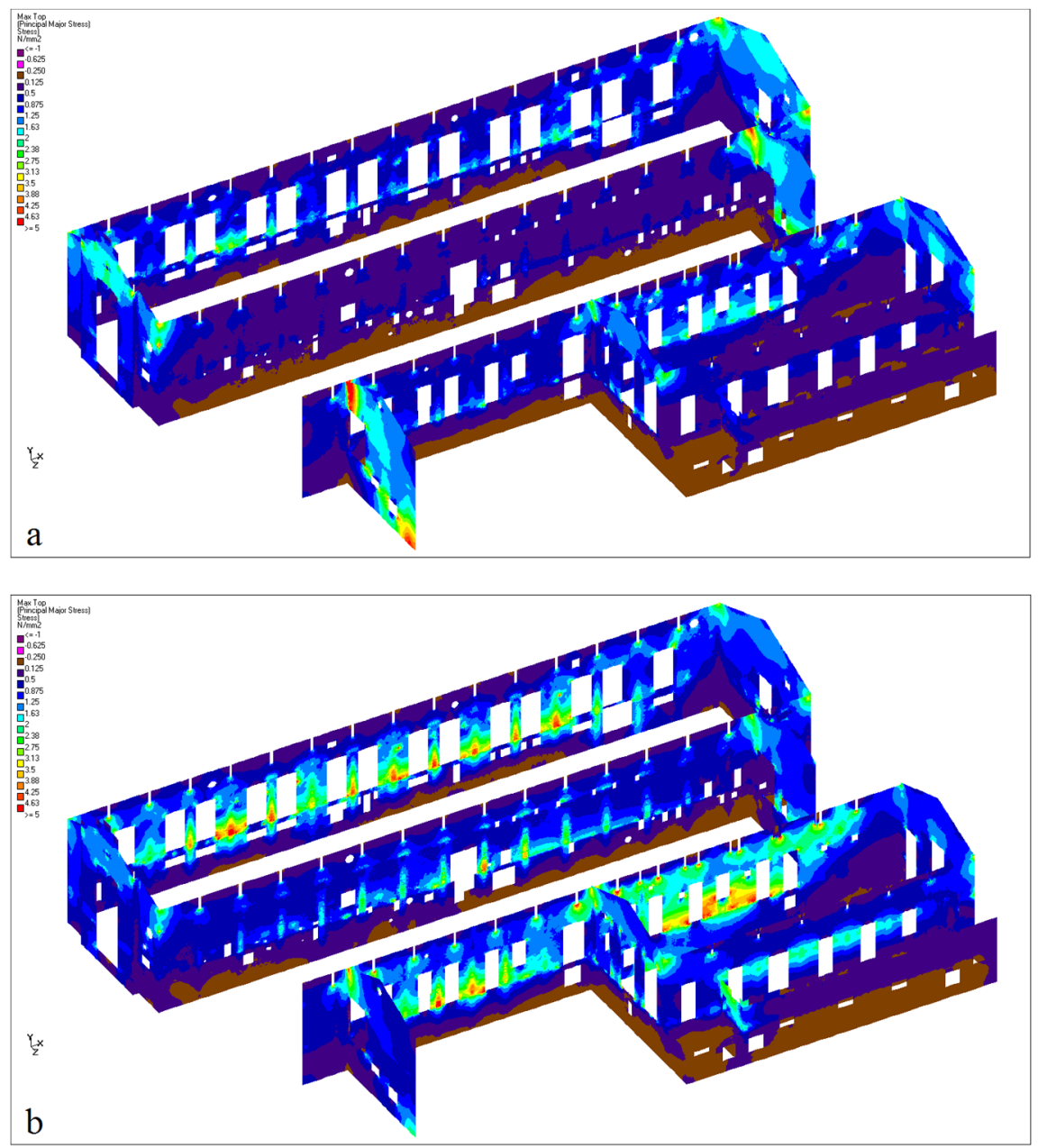

Figure 10: Maximum principal stress distributions under earthquake loading along (a) $\mathrm{X}$ and (b) $\mathrm{Z}$ directions. 


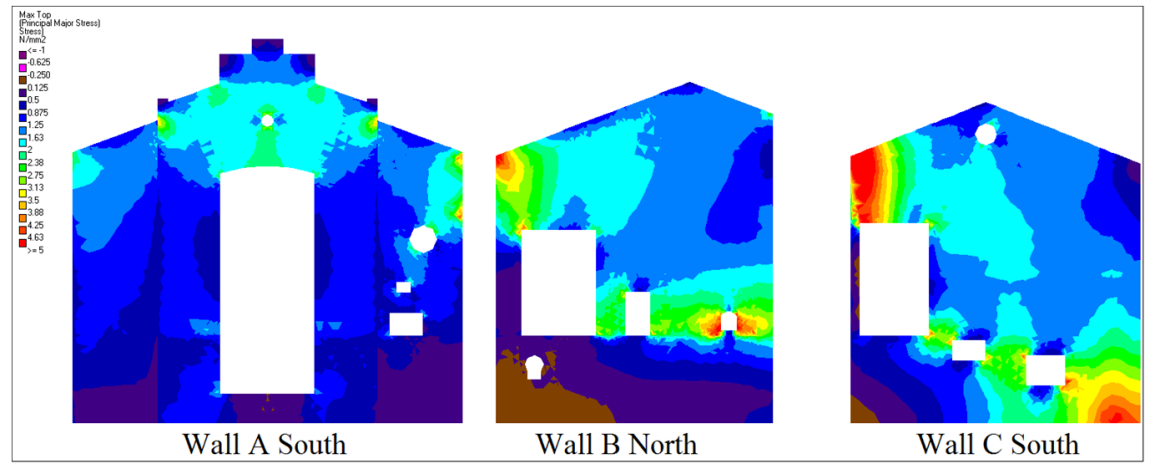

Figure 11: Maximum principal stress distributions for transverse walls under earthquake loading along $\mathrm{X}$ direction.

More specifically, regarding the transverse masonry walls, one can observe the maximum principal stress distribution under leading earthquake loading along $\mathrm{X}$ direction, in Figure 11. The exceedance of the tensile stresses due to the fact that the sidewalls are free standing, is easily observed. Quite notable is considered the fact that for the $1^{\text {st }}$ mode, only the mass of the building $\mathrm{C}$ flexible southern wall participates, with a corresponding period of $\mathrm{T}=1.01 \mathrm{sec}$ (Figure 12(a)). The $56^{\text {th }}$ mode shape of the dynamic analysis is also presented in Figure 12(b).

In Figure 13, the mass participation derived from the dynamic analysis is presented. One can observe that for direction $\mathrm{Z}$ the mass participates gradually rather than with significant notable steps, while for direction $\mathrm{X} 10 \%$ mass participation steps correspond to modes around 56, 82 and 125. The corresponding base shear forces are clearly illustrated in Figure 14.

In order to check the masonry resistance on the basis of the Eurocodes, local stresses were converted directly into force and moment terms, referring to ideal individual members (equivalent columns, lintels). Thus, design checks were performed by integrating the stresses along the specified segments.

Results showed that, for seismic action, the masonry walls exhibit large bending moments with simultaneous low axial forces. That observation assigns the structural behaviour of the masonry walls to that of a $10 \mathrm{~m}$ cantilever. An example is thoroughly illustrated in Figure 15 for the western wall of building A, where one can observe that the out-of-plane moment distribution is critical, considering the fact that the corresponding normal stresses are not sufficient. Remarkably, an $1860 \mathrm{kNm} / \mathrm{m}$ maximum out-of-plane moment is derived, which is compared to only approximately $50 \mathrm{kNm} / \mathrm{m}$ bending capacity. The examined segments are highlighted (red-coloured) in the figure below the corresponding diagrams.

In addition, the concrete frames' strength was examined by imposing displacements that were extracted by the main model analysis, and stress-limit design criteria were implemented [13]. The steel reinforcements exceeded resistance by approximately $60 \%$. Finally, the steel roofs were also found to be inadequate. 


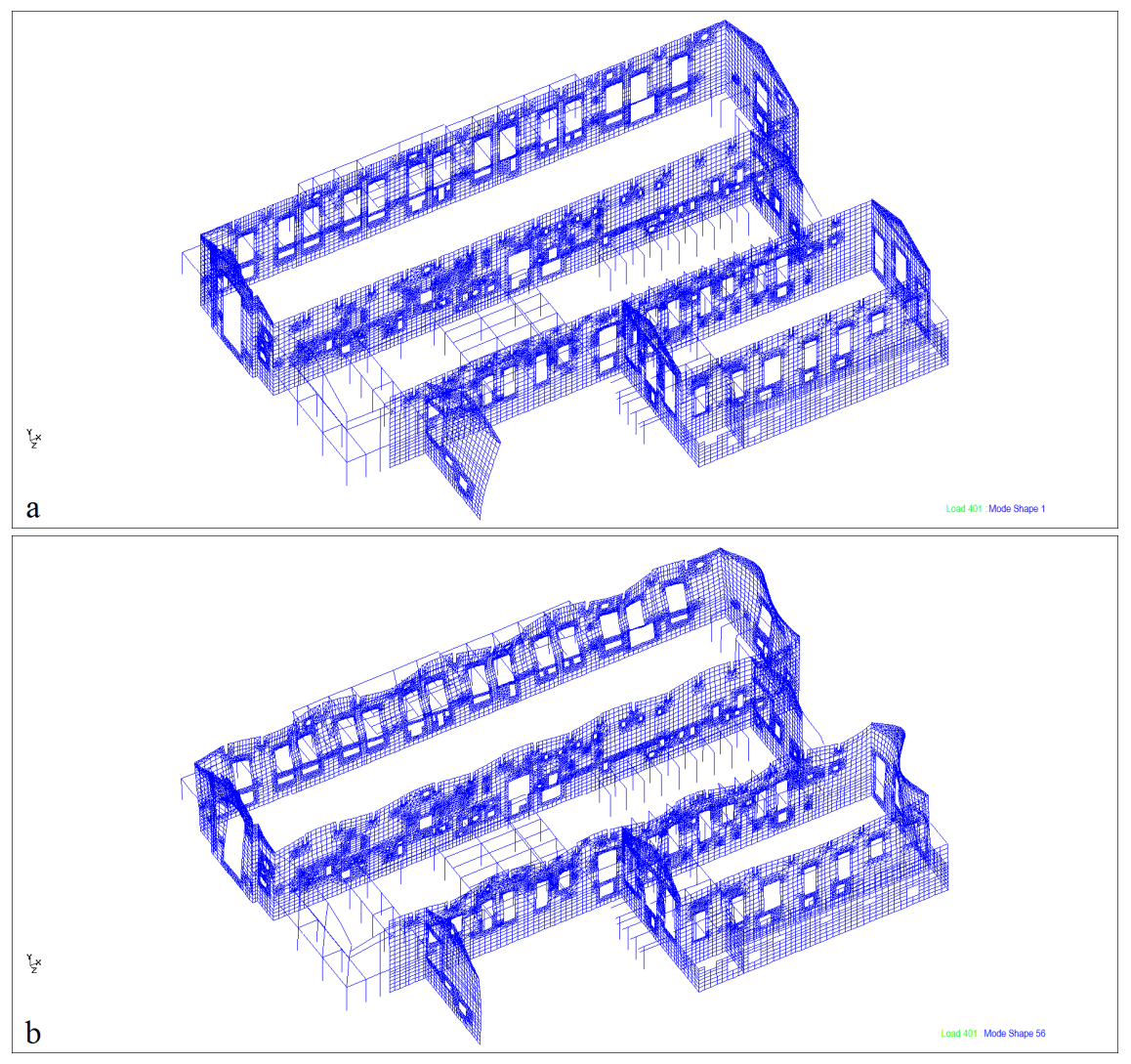

Figure 12: Shape deflections for the corresponding modes: (a) $1(1.01 \mathrm{sec})$ and (b) $56(0.16 \mathrm{sec})$.

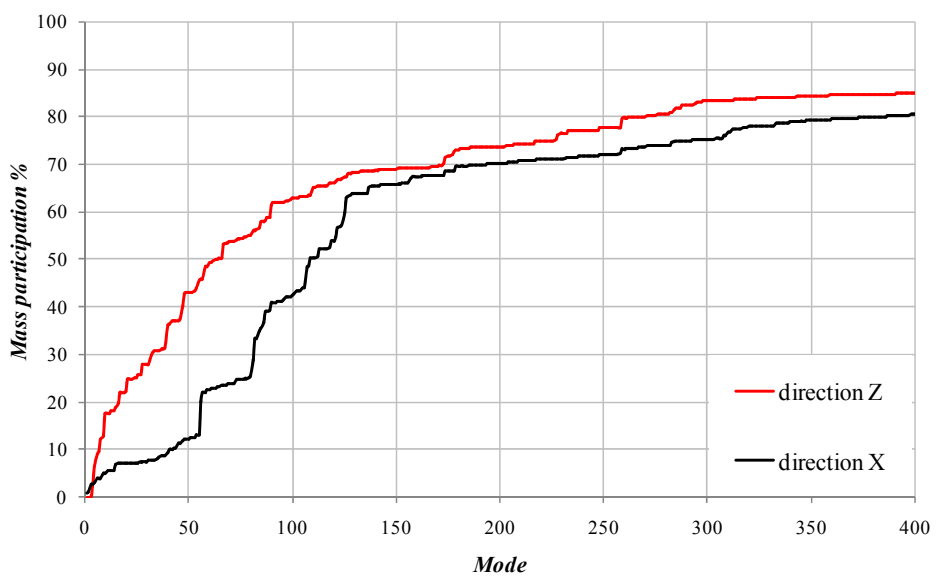

Figure 13: Comparison of mass participation between directions $\mathrm{X}$ and $\mathrm{Z}$. 


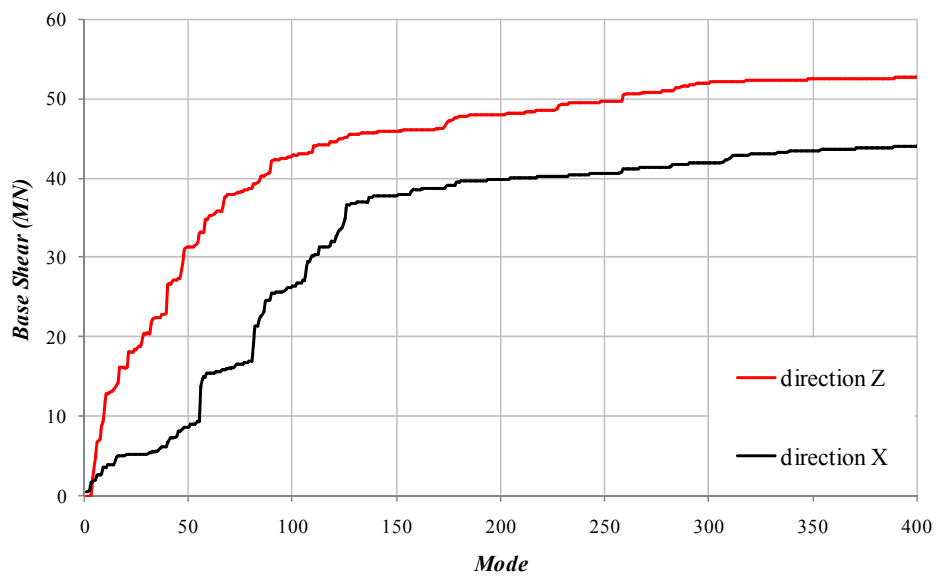

Figure 14: Comparison of base shear forces between directions $\mathrm{X}$ and $\mathrm{Z}$.

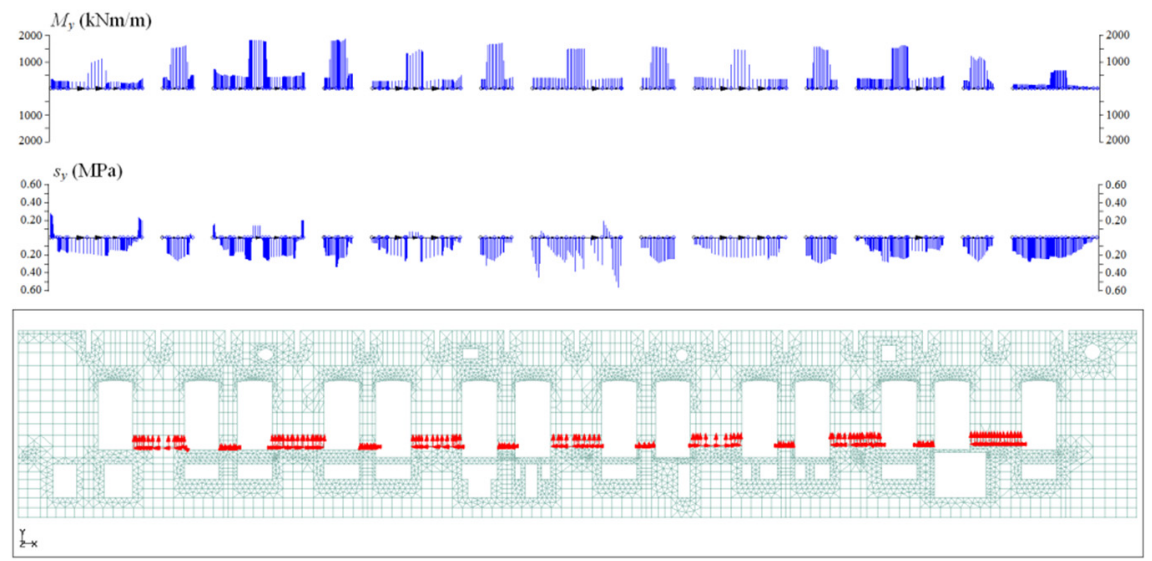

Figure 15: Out-of-plane moment $\left(M_{y}\right)$ and stress $\left(s_{y}\right)$ distributions of the western wall segments under earthquake loading along $\mathrm{Z}$ direction.

\section{Conclusions}

The investigation in this study focuses on the structural response of a historical masonry structure. The interventions made over the years are comprehensively described, whilst the reliable determination of the masonry mechanical properties is highlighted, since it is considered crucial for the assessment of the overall response of the structure. Destructive and non-destructive methods that were carried out are described herein, as are numerical analyses that were performed in order to locate critical stress areas. For the remaining capacity evaluation of 
the structural elements, the design principles per European and British Standards were implemented. Finally, a numerical investigation via dynamic analyses is demonstrated. The results indicate the significant vulnerability of unrestrained masonry walls, especially with deteriorated properties, under seismic excitation.

\section{References}

[1] Tomaževič, M., Earthquake-resistant design of masonry buildings, Imperial College Press, 1999.

[2] Paulay, T. \& Priestley, M. Seismic design of reinforced concrete and masonry buildings. Wiley Interscience Publication, USA, 1992.

[3] Karantoni, F., Masonry structures - design and repair, 2nd Edition, Papasotiriou (in Greek), 2011.

[4] Oliveira, C.S., Seismic Vulnerability of Historical Constructions: A Contribution, Bulletin of Earthquake Engineering, 1, pp. 37-82, 2003.

[5] Saloustros, S., Pelà, L., Roca, P. and Portal J., Assessment of structural damage in historical constructions using numerical models: the case of the church of the Poblet Monastery, Proc. of the $9^{\text {th }}$ Int. Conf. on Structural Analysis of Historical Constructions, Mexico City, Mexico, October 2014.

[6] Petromichelakis, Y., Saloustros, S. and Pelà, L., Seismic assessment of historical masonry construction including uncertainty, Aseismic design of structures and lifelines (EuroDyn 2014), Porto, Portugal, June 30, 2014.

[7] Bentley Systems Incorporated, STAAD.Pro V8i Structural Analysis and Design Software, California, USA, 2007.

[8] European Committee for Standardization, Eurocode 1 - Actions on structures, European Standard EN 1991, Brussels, Belgium, 2002.

[9] European Committee for Standardization, Eurocode 2 - Design of concrete structures - Part 1-1: general rules and rules for buildings, European Standard EN 1992, Brussels, Belgium, 2004.

[10] European Committee for Standardization, Eurocode 3 - Design of steel structures - Part 1-1: general rules and rules for buildings, European Standard EN 1993, Brussels, Belgium, 2005.

[11] European Committee for Standardization, Eurocode 6 - Design of masonry structures- Part 1.1: General rules for reinforced and unreinforced masonry structures, European Standard EN 1996-1-1, Brussels, Belgium, 2005.

[12] European Committee for Standardization. Eurocode 8 - Design of structures for earthquake resistance, European Standard EN 1990, Brussels, Belgium, 2002.

[13] Codes of Practice Committee, The structural use of normal reinforced concrete in buildings, CP 114, The Structural Engineer, 27(4), 1948.

[14] British Standards Institution, Cold Twisted Steel Bars for Concrete Reinforcement, BS1144, London, 1943.

[15] SeismoMatch v.2.1.0, Seismosoft, www.seismosoft.com. 